\title{
PRESERVAÇÃO DO NON-REFOULEMENT COMO JUS COGENS: ALCANCE E LIMITES DA RESERVA DO POSSÍVEL
}

\section{PRESERVATION OF THE NON-REFOULEMENT AS JUS COGENS: SCOPE AND LIMITS OF THE RESERVE FOR THE POSSIBLE}

\author{
Luciana de Aboim Machado \\ Miguel Kfouri Neto ${ }^{2}$ \\ Yuri Matheus Araujo Matos ${ }^{3}$ \\ Hélcio Kronberg3
}

\section{Resumo}

O desrespeito ao non-refoulement, assim como a sua aplicação indevida, é passível de controle de convencionalidade pelo Judiciário interno. Examina-se, em interpretação ampliativa do seu alcance, a vedação à expulsão administrativa de refugiado para local seguro, mesmo quando ausente prejuízo concreto na sua permanência em solo nacional. Quanto a este, a possibilidade de alegação, alcance e os limites jurídicos da reserva do possível. Caso aplicável ao caso, técnicas de assentamento ordenado de refugiados, para evitar a expulsão pura e simples, e o seu controle jurisdicional, através de sentença estruturante.

Palavras-chave: Refugiados. Non-refoulement. Juridicidadade. Proporcionalidade. Convencionalidade.

\footnotetext{
${ }^{1}$ Doutora em Direito (USP). Pós-doutora em Direito (UFBA e Università Degli Studi G. d'Annunzio/Itália). Mestre em Direito pela PUC/SP. Coordenadora do Programa de Pós-Graduação Stricto Sensu em Direito e Professora Associada da UFS. Vice-presidente da Asociación Iberoamericana de Derecho del Trabajo y de la Seguridad Social Guillermo Cabanellas. Consultora da Ergon Associates (London). Líder do Grupo de Pesquisa Eficácia dos Direitos Humanos e Fundamentais: seus reflexos nas relações sociais (GEDH/UFS/CNPq). E-mail: lucianags.adv@uol.com.br;

${ }^{2}$ Pós-Doutor em Ciências Jurídico-Civis junto à Faculdade de Direito da Universidade de Lisboa (2013-2014). Doutor em Direito das Relações Sociais pela Pontifícia Universidade Católica de São Paulo (2005). Mestre em Direito das Relações Sociais pela Universidade Estadual de Londrina (1994). Bacharel em Direito pela Universidade Estadual de Maringá (1981). Licenciado em Letras-Português pela Pontifícia Universidade Católica do Paraná (1972). Professor-Doutor integrante do Corpo Docente Permanente do Programa de Doutorado e Mestrado em Direito Empresarial e Cidadania do Centro Universitário Curitiba.

${ }^{3}$ Mestrando em Direito (PRODIR/UFS). Bolsista (Capes). Membro do do Grupo de Pesquisa Eficácia dos Direitos Humanos e Fundamentais: seus reflexos nas relações sociais (GEDH/UFS/CNPq). Trabalho desenvolvido, no ano passado, durante pesquisa como bolsista PIBIC remunerado pela CAPES no curso da graduação na UFS. Advogado. E-mail: ymam1996@hotmail.com.

${ }^{4}$ Investigador, membro dos grupos de pesquisa Cidadania Empresarial no Século XXI - UNICURITIBA Brasil, e integrante do grupo de Pesquisa Internacional - REDTH (Rede de Estudos em Direitos Humanos e Transnacionalidade).
} 


\begin{abstract}
The disrespect of the non-refoulement, such as the improper application of this, is liable of conventionality control by the internal judiciary. In expansive interpratation of the reach of the non-refoulement, the prohibition against administrative expulsion of refugees to a safe place is examinated, even when there is no concrete loss in their stay on national soil. About this, the possibility of claim, reach and the legal limits of the reserve for the possible. If it be applicable to the case, the orderly settlement techniques for refugees, to avoid outright expulsion, and the judicial control of it, through a structural sentence.
\end{abstract}

Keywords: Refugees. Non-refoulement. Juridicity. Proportionality. Conventionality.

\title{
INTRODUÇÃO
}

Vivencia-se a maior crise de refugiados da história recente, em números absolutos. O referido deslocamento forçado decorre de questões políticas, ambientais, econômicas, conflitos armados e outras graves violações dos direitos humanos. As vítimas e as suas famílias necessitam de local seguro e meios para a sua proteção e desenvolvimento humano. Entretanto, são recorrentes as notícias de vedação indiscriminada de recepção dos refugiados, ainda que estejam em situação de extremo risco - como em balsas no Mar Mediterrâneo, exemplificativamente.

O princípio non-refoulement foi positivado internacionalmente na década de $1950 \mathrm{com}$ o fim de evitar que as nações que recebem refugiados os devolvam para situações de risco. Trata-se de norma jus cogens, imperativa e inderrogável, independentemente da sua aceitação pelos Estados.

Todavia, identifica-se como problema central deste trabalho o desrespeito administrativo ao non-refoulement como jus cogens e aos consectários deste mandamento. É estudada a viabilidade e o alcance do respectivo exame jurisdicional interno, mediante o controle de convencionalidade. É verificada ainda a inviabilidade jurídica da concepção de expulsão e deportação de refugiados como ato estritamente político; e que há prejuízo socioeconômico real na subutilização produtiva e exploração indevida da mão-de-obra refugiada.

Com este fim foi realizado estudo de artigos científicos, livros, dissertações de mestrado e teses de doutorado. Realizou-se exame qualitativo e hermenêutico, através da interpretação 
axiológica, teleológica e humanitária, e seu cotejo com as notícias de omissão dolosa de proteção aos refugiados.

Obteve-se a fixação dos pontos mais relevantes, a serem aprofundados através de dados obtidos pelo Comitê Nacional para Refugiados (CONARE) e visitas técnicas à Superintendência da Polícia Federal de Sergipe e ao antigo Ministério do Trabalho em Sergipe. Esta foi a segunda etapa, ocorrida em 2017. Foram entrevistados durante aproximadamente duas horas, no antigo Ministério do Trabalho, dois auditores do trabalho, que preferiram a não identificação. Na Superintendência da Polícia Federal em Sergipe três policiais federais também foram entrevistados, mas solicitaram a não identificação.

O objetivo das entrevistas foi o exame qualitativo das dificuldades administrativas na promoção dos direitos dos migrantes, sejam eles refugiados ou não. Divide-se em a) questão documental; e b) concretização dos direitos humanos. Após o estudo da gravação das entrevistas, aproveita-se a análise do tema pelos profissionais mencionados, em sintonia com os dados obtidos do CONARE.

Entre 2018 e 2020 acompanhou-se a evolução dos dados sobre o tema, bem como a concretização da nova Lei de Migração. Em seguida, foi sistematizado o material. Por fim, estudada a viabilidade concreta das propostas apresentadas.

\section{MIGRANTE, EXILADO E REFUGIADO}

O deslocamento realizado pela população no espaço é compreendido como migração, gênero do qual são espécies a migração interna e a externa (BRASIL, 2017) ${ }^{4}$. A diferença entre esta e aquela reside na transposição da fronteira de um país. Ou seja, a subdivisão adotada atualmente está intrinsecamente relacionada à formação de sociedades suficientemente organizadas ao ponto do estabelecimento das suas fronteiras.

\footnotetext{
${ }^{4}$ Para os fins desta Lei, considera-se:

II - imigrante: pessoa nacional de outro país ou apátrida que trabalha ou reside e se estabelece temporária ou definitivamente no Brasil;

II - emigrante: brasileiro que se estabelece temporária ou definitivamente no exterior;

IV - residente fronteiriço: pessoa nacional de país limítrofe ou apátrida que conserva a sua residência habitual em município fronteiriço de país vizinho;

V - visitante: pessoa nacional de outro país ou apátrida que vem ao Brasil para estadas de curta duração, sem pretensão de se estabelecer temporária ou definitivamente no território nacional;

VI - apátrida: pessoa que não seja considerada como nacional por nenhum Estado, segundo a sua legislação, nos termos da Convenção sobre o Estatuto dos Apátridas, de 1954, promulgada pelo Decreto $\mathrm{n}^{\circ}$ 4.246, de 22 de maio de 2002, ou assim reconhecida pelo Estado brasileiro.
} 
A migração externa é subdividida em migração voluntária, refúgio, exílio e asilo. No primeiro caso o indivíduo passa a viver em nova localidade, em busca de melhores condições de vida e, geralmente, motivado por trabalho. Possui, portanto, a mais ampla das definições dentre os temas aqui estudados.

Já o segundo (refúgio) ocorre com a saída do local no qual a pessoa vive por motivo de perseguições ou catástrofes, gerando graves violações aos direitos humanos, e não somente a busca de melhores meios de vida - e esta é a sua principal diferença em relação à migração voluntária. Usualmente ocorre em caso de perseguições em função de etnia, nacionalidade, religião, ideologia, violação de direitos humanos, e até mesmo catástrofes ambientais. Buscam os refugiados apenas a preservação da sua vida e integridade mínima, assim como dos seus familiares.

O exílio, por fim, sucede contra a vontade do seu principal sujeito: a pessoa é "expulsa" da localidade na qual vive pelas lideranças locais. Está atrelado a motivações políticas. A última face da migração externa - asilo - se dá a pedido do indivíduo a um Estado diferente do seu, para que o proteja (permitindo a entrada) de perseguição do governo do país de origem. A posição política e crimes relacionados à segurança estatal são as razões mais comuns.

As principais razões para os fluxos migratórios são as questões políticas internas, conflitos internacionais, fatos da natureza e crises econômicas. Em relação aos que buscam refúgio no Brasil há concentração no primeiro e último casos, com consequência sobre grave violação aos direitos humanos ${ }^{5}$.

O Comitê Nacional para os Refugiados (CONARE) é o principal órgão responsável pela sistematização dos dados referentes aos refugiados no Brasil. É um órgão ministerial sob o âmbito do Ministério da Justiça e Segurança Pública que também está ligado ao Ministério das Relações Exteriores, Economia, Saúde, Educação, Departamento da Polícia Federal, Alto Comissariado das Nações Unidas para os Refugiados, além de Organizações não Governamentais.

Segundo o CONARE, o principal motivo do refúgio ao Brasil tem sido a grave e generalizada violação dos direitos humanos, sofrida como motivo principal por $51,1 \%$ dos refugiados em 2016, dentre os expressamente reconhecidos como refugiados. Em 14 de junho de 2018, todavia, o CONARE decidiu reconhecer a situação de "grave e generalizada violação

\footnotetext{
5 Tanto a dignidade humana como os direitos não são elementos isolados e, também, não são dados com antecedência, mas sim construídos passo a passo pela própria comunidade ou grupo afetado, o que lhes outorga $\mathrm{m}$ caráter de direitos em movimento que se podem gerar e revisar através da metodologia que se propõe. (FLORES, 2009, p. 117)
} 
de direitos humanos" na Venezuela, com fundamento no inciso III do art. $1^{\circ}$ da Lei ${ }^{\circ}$ 9.474, de 1997 (BRASIL, 1997), fato que ampliará os números referentes ao respectivo pedido de refúgio 6 .

O segundo principal motivo até 2016 foi a perseguição política, responsável pela fuga de $22,5 \%$. Com números bastante próximos vem a reunião familiar: $22,3 \%$, e então a perseguição religiosa $(3,18 \%)$, e, por último, a perseguição por grupo social $(0,85 \%)$.

O perfil característico do refugiado (CONARE, 2016 e CONARE, 2017), desconsiderados os dados sobre os Venezuelanos, remetia em 2016 a um homem (70,7\%, sendo 29,3\% de mulheres), possuindo entre 18 e 39 anos (65,3\% estão nesta faixa etária), sírio (no Brasil, 2077 sírios) ou angolano (1.480 eram provenientes da nação da costa ocidental africana). Viviam no Sul do país (35\% do total), ou sudeste (31\%). Em seguida, a região Norte, com 25\%, e então centro-oeste, com $7 \%$ e, por último nordeste, com $1 \%$.

Em 2018 (CONARE, 2019) o perfil característico sofreu algumas alterações: passou a remeter a um homem (66\%, sendo 34\% de mulheres), possuindo entre 30 e 59 anos (14,64\% das mulheres e 27,35 dos homens estavam nesta faixa etária), sírio (51\%), com distribuição mais ampla no Brasil, em comparação à pesquisa de 2016.

Trata-se de pessoas com necessidade de proteção estatal específica, com o fim de afastamento da situação de risco e garantia de condição mínima de vida. Posteriormente, caso desejado, é feito o retorno ao local de origem ou outro, após a cessação da situação de risco. Por esta razão há regramento específico internacional, vinculante sobre o Brasil pelo princípio norteador do Direito Internacional Público do pacta sunt servanda e por possuir como pilar o dever de não devolução, (non-refoulement), matéria jus cogens.

\section{RELAÇÃO ENTRE O ORDENAMENTO JURÍDICO INTERNO E INTERNACIONAL}

Duas principais correntes explicam a relação entre o direito internacional e o direito interno: o dualismo e o monismo. Segundo a corrente dualista, ambos são ordens independentes e igualmente válidas, mas os tratados somente têm eficácia após o procedimento de incorporação. Para o dualismo radical é necessária lei em sentido formal para a incorporação

\footnotetext{
${ }^{6}$ Entretanto, em decorrência das citadas dificuldades no processamento dos pedidos de refúgio, não há ainda dados que incluam os venezuelanos: apenas compreende-se que correspondem a 52\% das solicitações em trâmite (CONARE, 2019).
} 
(SHAW, 2010, p. 115) ${ }^{7}$. O moderado, por sua vez, compreende ser suficiente ato infra legal, como o decreto (RAMOS, 2013, p. 259).

Para o monismo o direito internacional e o interno são um só (ordem jurídica única). O principal expoente do monismo internacionalista é Hans Kelsen: em caso de conflito, prevalece a norma internacional (KELSEN, 2009). A sua positivação está na Convenção de Viena de 1969, artigo 27, demonstrando a prevalência da Escola de Viena, da qual o integrou o referido autor. Para o monismo nacionalista, que possui Hegel como clássico defensor, o direito nacional prevalece em caso de conflito (HEGEL, 2010, p. 257-258). A semelhança entre ambos os entendimentos é que não é necessário o procedimento de incorporação ao direito interno.

Os tratados internacionais integram o ordenamento interno da seguinte maneira ${ }^{8}$ : quanto aos tratados comuns, em regra, possuem paridade normativa com as leis, após o processo de incorporação ${ }^{9}$. Em relação aos tratados de direitos humanos, por outro lado, segue-se a normativa do art. $5^{\circ}, \S \S 2^{\circ}$ e $3^{\circ}$, Constituição da República Federativa do Brasil (CRFB), com redação pela Emenda Constitucional n. 45/04). É o resumo do entendimento do Supremo Tribunal Federal sobre a matéria (SUPREMO TRIBUNAL FEDERAL, 2008): tratados assinados antes da Emenda Constitucional n. 45/04 possuem "status supralegal": estão hierarquicamente posicionados acima da lei, mas abaixo da Constituição Formal ${ }^{10}$. Em relação aos tratados internacionais assinados após a emenda constitucional, serão constitucionais desde que aprovados segundo o rito de Emenda à Constituição (poder constituinte derivado reformador).

Entretanto, os tratados não submetidos ao procedimento de incorporação sujeitam a ordem interna ao controle de convencionalidade, a depender da força normativa inerente ao conteúdo do seu tratado. Por tratar-se da matéria de maior relevância no direito internacional, qualquer tratado ou convenção de direitos humanos serve como parâmetro para o controle de

\footnotetext{
${ }^{7}$ Para o dualismo radical, havendo conflito entre norma internacional e a lei, há duas soluções: se o tratado não foi incorporado, não tem eficácia. Se foi, passou a ser norma interna. Logo, utiliza-se as técnicas de resolução de antinomias aparentes (hierarquia, especialidade e cronologia).

${ }^{8}$ Segundo a perspectiva internacionalista, entretanto, independe a forma como o país observa o tratado. Aplica-se a máxima pacta sunt servanda, e o descumprimento enseja responsabilização internacional do Estado. Não interessa o motivo (daí a existência do Incidente de Deslocamento de Competência). Há ilícito internacional no descumprimento por qualquer dos 3 poderes. Isto porque a Convenção de Vienta de 1968, em seu art. 27, segue o monismo internacionalista. O Brasil não apresentou ressalva ao mencionado dispositivo.

9 Para solução de conflitos, utiliza-se as técnicas de conflito aparente de normas: critério cronológico e da especialidade (pois são de semelhante hierarquia). Exemplificativamente, tratados para evitar a bitributação (caso das mercadorias importadas de países do GATT, isento do ICMS (Enunciados n. 20 e 71 da Súmula do Superior Tribunal de Justiça); tratados bilaterais de extradição.

${ }^{10}$ Exemplifica-se com a Convenção Americana de Direitos Humanos. Possui efeito paralisante sobre as normas permissivas constitucionais às restrições de direitos, como a prisão civil do depositário infiel.
} 
convencionalidade. Os incorporados à CRFB servem de paradigma para o controle abstrato. Os não incorporados, somente ao controle difuso (MAZZUOLI, 2009).

Independentemente da compreensão do ordenamento jurídico internacional como integrante ou não do interno, observa-se diferenças relevantes entre as espécies normativas do direito internacional, com hierarquia e força vinculativa entre si. O parâmetro não é a forma de criação, em geral, mas o conteúdo da norma ${ }^{11}$.

Os tratados de direitos humanos prevalecem sobre os demais, por sua importância ao assegurar a dignidade da pessoa humana. São normas de hierarquia superior e de necessária aplicabilidade concreta às nações. Alguns destes tratam de normas com natureza jus cogens, de aplicabilidade obrigatória, conforme os arts. 53 e 64 da Convenção de Viena sobre o Direito dos Tratados (PIOVESAN, 2009).

Para que determinada norma seja considerada jus cogens, seu requisito é a relevância da matéria e a aceitação e reconhecimento pela sociedade internacional em sua totalidade. Prevalece atualmente o entendimento que, ainda que alguma nação rejeite determinada norma como jus cogens, seu relevante valor deve preponderar. Sobre a questão há duas correntes: a relativista e a universalista.

Para a corrente relativista, não existe uma moral universal. Ao contrário, as regras sobre a moral variam conforme o lugar, em virtude da diversidade cultural (SANTOS, 1997). Nesta ótica, os padrões culturais e morais influenciam na forma como a sociedade concebe a noção de "direitos humanos". Pode ser utilizada como fundamento para afastar a força normativa dos tratados de direitos humanos que trazem disposição jus cogens, bem como sua aplicabilidade direta e imediata aos destinatários.

Para o universalismo, a diversidade cultural não pode ser invocada com o objetivo de se justificar a prática de violações aos direitos humanos (TAVARES, 2005). Nesse sentido, a noção de respeito aos "direitos humanos" deveria ser única em todos os locais do mundo. Há um padrão mínimo de proteção a ser observado. À luz da ótica Kantiana, busca-se tutelar a prevalência dos Direitos Humanos

Em 1993 ocorreu em Viena a Segunda Conferência Mundial de Direitos Humanos. Nela prevaleceu a corrente universalista, tal qual se extrai do $\S 5^{\circ}$ do Programa de Ação de Viena, verbis:

Todos os Direitos do homem são universais, indivisíveis, interdependentes e interrelacionados. A comunidade internacional tem de considerar globalmente os Direitos do homem, de forma justa e equitativa e com igual ênfase. Embora se devam ter sempre presente o

${ }^{11}$ À exceção da Carta da ONU, que prevalece sobre os tratados e convenções. 
significado das especificidades nacionais e regionais e os antecedentes históricos, culturais e religiosos, compete aos Estados, independentemente dos seus sistemas político, económico e cultural, promover e proteger todos os Direitos do homem e liberdades fundamentais.

Como consequência da histórica universalista, os tratados de direitos humanos de reconhecimento relevante pelas nações, erigidos ao patamar de costumes internacionais constituem normas inderrogáveis, de máxima exigência pelos Estados. A caracterização como costume depende do seu aspecto objetivo (reiteração comportamental) e subjetivo (crença na justeza da conduta). Existentes os requisitos e observada a relevância material dos costumes, alguns tratados de direitos humanos são considerados jus cogens $^{12}$; dentre eles, o princípio da não devolução dos refugiados - non-refoulement.

\section{CONTROLE JUDICIAL DO DESCUMPRIMENTO DA NÃO DEVOLUÇÃO}

Embora não seja fato jurídico recente, a migração forçada obteve positivação internacional em 1951, com a Convenção Relativa ao Estatuto dos Refugiados de 1951. No seu artigo $1^{\circ}$ conceituou o refugiado como alguém que

Tendo um temor bem fundado de ser perseguida por motivos de raça, religião, nacionalidade, grupo social ou opiniões políticas, se encontra fora do país de sua nacionalidade e que não pode ou, em virtude desse temor, não quer valer-se da proteção desse país.

Com aceitação do indivíduo na condição refugiado, o Estado passa a ter, em relação a ele, os deveres que objetivem a garantia da sua dignidade (SARLET, 2002, p. 62) ${ }^{13}$. Em relação à recepção das vítimas do deslocamento forçado, o dever basilar de recepção consagra o marco do humanismo político, não como obrigação internacional subjacente aos atos de império, mas fruto de um enforcement jurídico (JUBILUT, 2007, p. 81).

Por este motivo o art. 33 da mencionada convenção prevê expressamente:

Nenhum dos Estados Membros expulsará ou rechaçará, de maneira alguma, um refugiado para as fronteiras dos territórios em que a sua

\footnotetext{
12 Os tratados de direitos humanos são vinculantes até mesmo aos terceiros estados não contratantes. Os tratados comuns somente os alcançam em relação aos direitos (há presunção de consentimento, até posicionamento contrário expresso do terceiro). Quanto às obrigações, o terceiro Estado deve aceitar expressamente, por escrito. Já o tratado de direitos humanos, cria obrigações a terceiro diretamente, como um costume internacional.

${ }^{13}$ Para Ingo Wolfgang Sarlet, a dignidade é "a qualidade intrínseca e distintiva de cada ser humano que o faz merecedor do mesmo respeito e consideração por parte do Estado e da comunidade, implicando, neste sentido, um complexo de direitos e deveres fundamentais que assegurem a pessoa tanto contra todo e qualquer ato de cunho degradante e desumano, como venham a lhe garantir as condições existenciais mínimas para uma vida saudável, além de propiciar e promover sua participação ativa e co-responsável nos destinos da própria existência e da vida em comunhão com os demais seres humanos."
} 
vida ou a sua liberdade seja ameaçada em virtude da sua raça, da sua religião, da sua nacionalidade, do grupo social a que pertence ou das suas opiniões políticas.

Trata-se do principio non-refoulement, que objetiva a proteção da dignidade mínima dos sujeitos de fluxos migratórios forçados. É norma reconhecida pela comunidade internacional dos Estados como um todo. Assim, nenhuma derrogação é permitida do non-refoulement. Portanto, trata-se de norma jus cogens (PAULA, 2006) ${ }^{14}$.

É rígida a concepção que o país que recebe refugiados possui o dever de não devolver a local no qual eles possam estar em risco. Não se trata somente da sua origem, mas qualquer outra região que lhes cause perigo de vida, tal qual o abandono no mar ou em país de perseguição semelhante ao do qual vieram.

No Brasil competem ao Executivo as decisões inerentes à recepção dos refugiados. Entretanto, observar o non-refoulement não é ato discricionário, razão pela qual sujeito ao controle amplo de juridicidade. Ademais, ainda que observado o princípio, a decisão Executiva que acarrete prejuízo ao interessado deve ser fundamentada, em atendimento ao dever constitucional de fundamentação e publicidade das decisões administrativas e judiciais ${ }^{15}$.

A expulsão desnecessária, inadequada ou desproporcional de refugiado para um local não havendo prejuízo na manutenção em solo nacional ou designação a outro país que lhe traga menor perigo - é passível de controle de juridicidade. Ainda que não examine o mérito administrativo, estará sob exame a proporcionalidade, sendo possivelmente ferida a legalidade, pois princípios possuem força normativa e a sua correta ponderação é exigência do administrador. Logo, é relevante o controle jurisdicional para a proteção dos refugiados, em atendimento ao acesso à tutela jurisdicional justa e ao sistema de dualidade brasileiro ${ }^{16}$.

Além do controle da proporcionalidade do ato administrativo de expulsão, é cabível o exame jurisdicional da designação como migrante ou refugiado. Isto porque as cláusulas de inexpulsabilidade dos refugiados não são extensivas aos imigrantes em geral. Com o fim de afastar refugiados, diversos países os têm considerado como migrantes (PAULA, 2006).

\footnotetext{
${ }^{14}$ A Declaração de Cartagena de 1984, a Declaração de San José sobre os Refugiados e Pessoas Deslocadas de 1994 e a Declaração e Plano de Ação do México para Fortalecer a Proteção Internacional dos Refugiados na América Latina de 2004, reafirmaram a natureza jus cogens do princípio do non-refoulement.

${ }^{15}$ Deve-se observar ainda que é vedada a deportação coletiva, prática condenada expressamente pelo Tribunal Penal Internacional e pela legislação brasileira (BRASIL, 2017, art. $3^{\circ}$, XXII). Ademais, é proibido deportar refugiados para um país no qual não esteja comprovada a sua segurança.

16 "Estamos falando não da aplicação concreta do dinheiro distribuído, mas da própria distribuição do poder político como forma de complementar e aprofundar os aspectos meramente formais dos processos democráticos" (FLORES, 2009).
} 
A diferenciação entre migrantes e refugiados compete ao Executivo no Brasil. Da incorreta aferição pelo Executivo é possível o controle externo pelo Judiciário ${ }^{17}$. A deportação ou expulsão de refugiado como migrante fere o elemento finalidade específica do ato administrativo.

O fundamento de direito material do controle judicial em ambos os casos reside no citado art. 33 da Convenção Relativa ao Estatuto dos Refugiados de 1951. Logo, o Judiciário possui o dever de ir além do ordenamento pátrio e analisar o respeito à norma internacional de direitos humanos, que além de força supralegal e eficácia vinculante, possui natureza jus cogens.

A relevância desta concepção está na escassez de tutela jurisdicional interna acerca do referido problema. A maior parte da análise sobre esse caso está nas Cortes Internacionais, que têm se apresentado mais propensas ao exame do tema: "no que tange à jurisprudência brasileira verifica-se que ela é escassa no que concerne ao tema dos refugiados, existindo apenas 18 julgados sobre a questão" (JUBILUT, 2007, p. 102-103) ${ }^{18}$.

\footnotetext{
${ }^{17}$ AGRAVO DE INSTRUMENTO. ESTRANGEIRO. DECLARAÇÃO DA CONDIÇÃO DE REFUGIADO. GUERRA NO PAÍS DE ORIGEM. ALTO GRAU DE DISCRICIONARIEDADE DA ADMINISTRAÇÃO.

1. O controle de estrangeiros no território brasileiro quanto à entrada, permanência e saída compulsória é matéria cometida à Administração com elevado grau de discricionariedade. 2. Os compromissos brasileiros com a proteção dos direitos humanos não afastam a discricionariedade no exame dos casos individuais de pedido de proteção. Tal exame de conveniência deflui da responsabilidade diplomática cometida ao Chefe do Executivo, em exercício de soberania estatal perante a sociedade internacional, e revela circunstâncias delicadas de responsabilidades e ônus nesse campo. 3. Não reconhecida a condição de refugiado após conclusão de regular processo administrativo, não cabe ao Poder Judiciário intervir para modificar a decisão da administração. É pertinente a ordem de saída do Brasil sob pena de deportação, observado que implementada uma ou outra situação não há restrição para que se
} postule imigração por outras formas disponíveis.

TRF-4, $3^{\text {a }}$ Turma. AGRAVO DE INSTRUMENTO n. 37636 PR 2007.04.00.037636-5. Relator: Marcelo de Nardi. Julgamento em 19 fev 2008.

${ }^{18}$ Complementa a autora que "Nos julgados do Supremo Tribunal Federal, os casos têm natureza variada: (1) há um caso que versa sobre decisão negativa no procedimento de determinação do status de refugiado - Mandado de Segurança 24.304/DF, de 04.09.2002; (2) dois casos que versam sobre pedido de vedação de expulsão em função de a pessoa ser refugiada - Habeas Corpus 69.268/DF, de 22.05.1992, e Habeas Corpus 71.935/SC, de 27.10.1994; (3) nove casos que versam sobre pedido de vedação de extradição alegando a condição de refugiada da pessoa a ser extraditada - Extradição 232, de 09.10.1961, Extradição 419/ES, de 24.04.1985, Extradição 524/PG, de 31.10.1990, Habeas Corpus 81176/AL, de 08.11.2001, Segunda questão de ordem em extradição 785/ME, de 13.09.2001, Reclamação 2.069/DF, de 27.06.2002, Agravo Regimental nos autos apartados da Extradição 783/ME, de 26.06.2002, Habeas Corpus 83.501/DF, de 29.10.2003, Embargos Declaratórios na Extradição 785/ ME, de 27.3.2003; (4) e três casos que tratam de relaxamento da prisão para extradição quando é feita solicitação de refúgio - Habeas Corpus 81.127/DF, de 28.11.2001, Segunda questão de ordem em extradição 783/ME, de 28.11.2001, Segunda questão de ordem em extradição 784/ME, de 28.11.2001.230.

Os julgados do Superior Tribunal de Justiça são em número de três (Agravo Regimental do Mandado de Segurança 12.212/DF; Habeas corpus 36.033/DF; e Habeas corpus 32.622/DF) e denotam, por um lado, o desconhecimento do tema dos refugiados (ao se referirem ao pedido de reconhecimento como refugiado como um pedido de reconhecimento como "foragido" 231 ou ao se referirem à lei brasileira sobre refugiados como a Lei 4.947/1997, quando o correto é lei 9.474/1997232 ) e, por outro lado, a tendência de ir sempre a favor das decisões do Comitê Nacional para Refugiados [CONARE] ainda quando verificam que a motivação para a negativa do reconhecimento do status de refugiado é "lacônica". Pelo exposto, pode-se dizer que, apesar de na esfera universal não existir jurisprudência sobre refúgio e de a jurisprudência sobre asilo ser escassa, e no caso do ordenamento jurídico 
O acesso à tutela jurisdicional interna é fática e juridicamente mais simples que às Cortes Internacionais. Isto decorre da prestação de serviços jurídicos aos pobres; coletividade da tutela; operacionalização do sistema interno; e harmonização do aparato judicial (CAPELLETTI, 1988). Logo, ampliar o debate e aperfeiçoar a técnica do Judiciário interno é socialmente mais eficaz que buscar guarida no sistema Internacional de Direitos Humanos ${ }^{19}$.

É importante destacar a relevância da exigência da proporcionalidade para o ato de expulsão. A ausência de prejuízo na manutenção em solo nacional fere o pressuposto da necessidade, tornando o ato administrativo ilegal. Entretanto, nas demandas que envolvem deveres administrativos estatais a ordem jurisdicional interna usualmente se depara com os problemas do consequencialismo e da reserva do possível. Trata-se de argumentos que poderiam fundamentar, em tese, a expulsão, desde que para local no qual o refugiado não corra perigo. Todavia, conforme será demonstrado, não há substrato jurídico ou econômico para tal argumentação.

\section{RESERVA DO POSSÍVEL E BENEFÍCIO ECONÔMICO DA RECEPÇÃo ORDENADA}

A diferença entre o direito subjetivo e a sua aplicabilidade é o cerne do questionamento sobre o consequencialismo e a reserva do possível. Para a ética Kantiana, os direitos não podem ser confundidos com sua aplicabilidade. Aqueles são inatos, mas esta variável (KANT, 1985, p. 87). Para Herrera Flores, por outro lado, a construção dos direitos está intrinsecamente relacionada à estruturação da sociedade e à luta (perspectiva histórico-dialética) (FLORES, Teoria Crítica dos Direitos Humanos, 2009).

brasileiro a produção jurisprudencial sobre o tema ser ínfima, o Direito Internacional dos Refugiados tem servido de base para o estabelecimento de jurisprudência nos sistemas regionais, sendo que no continente europeu, talvez em função da maior coesão e da integração dos Estados dessa área geográfica, os avanços na matéria são significativos, o que denota a possibilidade de se considerar que o Direito Internacional dos Refugiados apresenta a jurisprudência como uma de suas fontes".

Após 13 (treze) anos do seu estudo, a pesquisa jurisprudencial interna revele reduzido acréscimo no número de casos.

${ }^{19} \mathrm{O}$ recurso às Cortes Internacionais, entretanto, ainda é relevante, pois em Cortes Supremas nacionais há decisões deturpadas sobre o non-refoulement: de que ele veda a expulsão de um território específico para outro - logo, a negativa irrestrita à recepção não violaria a não-devolução. Da mesma maneira, a expulsão para local arbitrariamente escolhido, sem prejuízo na permanência do refugiado em solo nacional ou ida para local menos arriscado, seria um ato estritamente político. Exemplificativamente, esta argumentação foi acolhida pela Suprema Corte dos Estados Unidos, no caso da não recepção de haitianos que foram impedidos de entrar no território dos Estados Unidos (caso 10.675) (JUBILUT, 2007, p. 100; ARAÚJO, 2015; TÉLÉMAQUE, 2012). 
$\mathrm{Na}$ essência do debate reside a compreensão que inexiste direito absoluto. Logo, possível a restrição por normas em sentido oposto (uma limita a outra). Entretanto, há limites às restrições: um núcleo essencial intransponível. Trata-se da teoria dos limites dos limites (Schranken-Schranken) (FREITAS, 2007).

A aplicação dos ditames do Schranken-Schranken ao controle jurisdicional de convencionalidade em atenção a aplicabilidade do princípio do non-refoulement leva aos seguintes postulados: a) não há fundamentação jurídica que justifique a expulsão de qualquer pessoa para lugar de risco (dignidade da pessoa humana); b) ainda que a expulsão seja para lugar não arriscado, deve seguir a necessidade, adequação, proporcionalidade em sentido estrito, com justificativa específica jurídico-econômica, pública, após o devido processo legal, e se provada a inviabilidade concreta de reassentamento pacífico (exigência de clareza, precisão e proporcionalidade); c) vedada restrição a grupo específico ou através de padrão não isonômico (limitações, em regra, de cunho geral e abstrato).

Reconhece-se que, em regra, não se inclui na atividade do Judiciário a determinação e a implementação de políticas públicas, pois ingerência indevida fere a separação dos poderes. Além disso, pode existir de fato a reserva do possível - efetivas restrições e impossibilidades financeiras estatais. Relaciona-se à teoria dos custos dos direitos: são serviços públicos que o governo presta em forma de tributos. Segundo esta, o direito nasceria da previsão orçamentária.

Ademais, o mínimo existencial dos indivíduos é fator limitador da reserva do possível, pois núcleo intangível dos direitos fundamentais, que atrai a intervenção judiciária (SUPREMO TRIBUNAL FEDERAL, ADPF 45, 2004). Assim proferiu o Ministro Celso de Mello no julgamento da ADPF n. 45, em 2004, citando o dilema das tragic choices de Guido Calabresi: "O Estado não poderá exonerar-se, dolosamente, do cumprimento das suas obrigações constitucionais".

Quanto ao procedimento, reconhece-se, segundo já manifestou o STF(ADPF 45/2004) que o ente público pode se eximir da obrigação, caso demonstre em juízo a falta de recursos orçamentários, em uma demonstração efetiva (e não apenas alegação genérica); vale dizer, a real comprovação de que é impossível efetuar o remanejamento de outras verbas.

É relevante a compreensão do limite do direito por outro direito: o Executivo também tem poder para definir qual prevalece - mérito administrativo - desde que observada a proporcionalidade. Mister a compreensão que a substituição da discricionariedade 
administrativa pela jurisdicional é igualmente danosa (SANTOS, 2017, p. 114) ${ }^{20}$. Daí a razão do uso de parâmetros jurídicos objetivos de exame da necessidade do ato administrativo, pois o desproporcional é ilegal. No caso concreto da motivação econômica da expulsão de refugiados, constata-se que o custo social da sua manutenção não deve ser isoladamente considerado, mas em conjunto com os benefícios da sua recepção.

Em virtude da diversidade da mão-de-obra imigrante (IAMAMOTO, 1993, P. 11, apud COUTO, 2020, P. 165) $)^{21}$, assim como os seus respectivos patrimônios e expectativa de acúmulo e destinação produtiva de bens, além do consumo, constata-se diversos reflexos econômicos a partir dos fluxos migratórios. Os trabalhos jurídico-econômicos apresentam esforço específico em estimar as várias elasticidades de substituição constante, com efeitos sobre as diferenças de salários, poder de compra, produtividade e gastos públicos com direitos prestacionais.

A partir de relevante mudança de metodologia nos trabalhos modernos, não se busca superficialmente mediar a correlação entre salários e os choques de oferta induzidos pela migração. Examina-se o incremento sobre a produtividade agregada e o indireto impacto sobre o poder de compra. O trabalho "Comment: on Estimating Elasticities of Substition", Borjas, Grogger e Hanson, das universidades de Harvard, Chicago e da Califórnia, respectivamente, é fundamental para a compreensão de que, especialmente no longo prazo, a imigração é economicamente benéfica (BORJAS, GROGGER e HANSON, 2012).

A análise sob uma perspectiva macroeconômica leva-nos à compreensão de que os vícios socioeconômicos atrelados à migração residem exclusivamente nos excessos: a entrada completamente desordenada de migrantes em uma nação despreparada pode provocar distúrbios sociais no curto prazo.

A simples entrada de mão-de-obra, seja ela especializada ou não, significa contribuição significativa para o desenvolvimento econômico, pois o trabalhador paga impostos (pela renda e pelo consumo), financia serviços públicos e a assistência e apenas terá direito à previdência após os períodos de contribuição previstos em lei.

\footnotetext{
20 "É preciso ir em direção a um constitucionalismo que não faça uso das teses que desembocam, invariavelmente, em discricionariedades. É preciso dar um passo para além do esquema sujeito-objeto. Resgatemos a contribuição básica de Gadamer e Heidegger para fugirmos dessa subjetividade individualista”.

21 "A saída para a pobreza tende a ser visualizada exclusivamente através da construção de identidades coletivas, de novas formas de sociabilidade que dêem sustentação a uma moderna concepção de cidadania, mantida intocada a organização do mundo do trabalho."
} 
Aos migrantes são assegurados os direitos sociais em sentido amplo (ARENDT, 2009). Daí é decorrência lógica o argumento da "reserva do possível" (COUTO, 2020, p. 69)"22, usualmente apresentado em juízo pelo poder público quando devidos direitos prestacionais. Esta é, entretanto, economicamente contornável no caso em análise, através da organização na recepção dos migrantes.

Além do afastamento jurídico absoluto da reserva do possível na expulsão para local perigoso em virtude da imprescindibilidade e transitoriedade facultada ${ }^{23}$, a reserva do possível e não-recepção ou expulsão para outro país restam maculados pelos benefícios econômicos da recepção de refugiados.

Observe-se que o ônus da prova da reserva do possível é do Poder Público (SARLET e FIGUEIREDO, 2008). Este deve demonstrar in concreto a impossibilidade econômica de atendimento da demanda de manutenção do refugiado em solo nacional. Ela somente poderá ser alegada em casos extremos, de crises migratórias tão relevantes que possam abalar significativamente, no curto prazo, a economia do país, e não seja possível a compensação pelos benefícios econômicos da recepção.

Na experiência recente, todavia, o Brasil não vivencia algo sequer próximo da referida crise: conforme o CONARE, o número total de refugiados reconhecidos passou de 4.352, em 2011, para 4.604, em 2012, e então 5.308, em 2013, e 7.609, em 2014 (CONARE, 2016). No ano de 2015, chegou a 8.400. Até o final de 2016, o Brasil reconheceu um total de 9.552 refugiados de 82 nacionalidades, dentre os quais 8.522 foram por vias tradicional de elegibilidade, 713 por reassentamento e a 317 estendidos os direitos por vínculos familiares. Só os Venezuelanos saltaram de cerca de 230 pedidos em 2015 e 2016 para quase 3.000, de janeiro a abril de 2017 (nenhum pedido até então aprovado) (CONARE, 2017). Outros 5.000 tinham senha para entregarem documentos em 2018 (JORNAL NACIONAL, 2017). São os números de 2018: 161.057 solicitações de reconhecimento da condição de refugiados em trâmite e 11.231 pessoas refugiadas reconhecidas (CONARE, 2019). Constata-se, de fato, que o deferimento do pedido de refúgio não dispõe da celeridade exigida pelos casos concretos

\footnotetext{
22 "A crise econômica, as altas taxas de inflação, o desequilíbrio fiscal, o crescimento da burocracia e o poder das corporações, em especial o dos sindicatos, são apontados como produtos do Estado de bem-estar."

${ }^{23} \mathrm{O}$ primeiro fator significa que, caso o refugiado seja abandonado, o risco à sua vida e dignidade é tamanho que há uma concorrência desproporcional entre os princípios ponderados, sendo necessária no mínimo a manutenção do refugiado em proteção até que a ameaça seja substancialmente mitigada. Quanto à transitoriedade, o refugiado não possui o animus e direito subjetivo à permanência. Não integrará a sociedade que o acolhe, desfrutando tão somente do refúgio temporário. A perenidade da relação de abrigo é condicionada à vontade (demonstrada expressa ou tacitamente) do indivíduo e do Estado acolhedor.
} 
(LEITE, 2014). Conforme o CONARE, o Brasil analisava em 2016 uma média de 126 pedidos de refúgio, mensalmente (CONARE, 2017 e 2018).

Em alguns casos as análises dos pedidos de refúgio demoram mais de um ano ${ }^{24}$. Isto, contudo, não enseja a concepção de grave crise: proporcionalmente à população brasileira (aproximadamente 200 milhões de habitantes), o número de solicitações de refúgio é ínfimo. Logo, inexiste qualquer abalo econômico ${ }^{25}$.

Por fim, ainda que exista, no futuro, o caso extremo de uma crise de refugiados apta a abalar significativamente a economia nacional, sem expectativa de benefício no longo prazo, demonstrada taxativamente pela Administração Pública, a sua consequência jurídica não será a expulsão pura e simples, mas a distribuição espacial equitativa (nacional ou internacional) dos refugiados. Para este fim, relevante o estudo dos instrumentos de efetividade do controle de convencionalidade em casos de crises que possam abalar significativamente a economia nacional.

\section{INSTRUMENTOS DE EFETIVIDADE DO PRINCÍPIO DO NON-REFOULEMENT E APLICAÇÃO DO CONTROLE DE CONVENCIONALIDADE}

A atração da reserva do possível decorrente de relevante crise de refugiados não enseja a expulsão do refugiado, em hipótese alguma. Para resolver a questão, com a entrada do estrangeiro será indicada a sua profissionalização e escolaridade, em nível técnico e científico, para que haja a possibilidade de prática da profissão na região acolhedora pelos que estão capacitados (MATOS e BRITTO, 2018). Através do cruzamento dos índices de desemprego e

\footnotetext{
${ }^{24}$ Para a celeridade na distinção entre migrantes e refugiados, propõe-se a sua diferenciação de acordo com diretrizes pré-estabelecidas em âmbito MERCOSUL, criando-se assim uma presunção iuris tantum da natureza do movimento de determinados grupos humanos, a depender da região de origem e condição física em que se encontra o migrante. Desta maneira permite-se definição precisa de quem é refugiado e quem é migrante, utilizando-se de presunção (admitida, por óbvio, a prova em contrário), estabelecida pelo Ministério da Justiça e Segurança Pública, no caso do Brasil. Faz-se importante ressaltar, neste ponto, que uma diferenciação pautada na etnia, cultura ou religião é manifestamente inconstitucional, e a presunção de refugiado deve servir apenas para ampliar o acesso dos mais necessitados ao mínimo existencial, não podendo ser utilizada, em hipótese alguma, como parâmetro para afastar dos originários de outras localidades a concessão do refúgio. O método de concessão dos pedidos de permanência será mantido do mesmo modo, sendo concedida apenas uma oportunidade, além das já existentes, aos originários de outras regiões conflituosas. Com este fim, a distinção não ocorrerá somente por país, mas observando critérios mais específicos. Exemplificativamente, grupos étnicos ou religiosos específicos, cidades ou regiões metropolitanas, gênero ou orientação sexual, a depender do local de origem.

${ }^{25}$ Quanto à emissão de carteiras de trabalho em Sergipe, ao todo, o setor de emissão informou que cerca de 20 carteiras semanais são concedidas aos estrangeiros, bem como renovações, devido ao término do prazo anteriormente concedido. Trata-se de procedimento muito mais simplificado que o de reconhecimento de refúgio, razão pela qual esta pesquisa não identificou relevantes problemas no trabalho do antigo Ministério do Trabalho em Sergipe.
} 
vagas abertas de emprego por área de trabalho, pode-se indicar o melhor local para envio do refugiado em solo nacional, com célere alocação no mercado de trabalho (ROGUED, 2009).

Acordo em nível MERCOSUL e OMC permitirá um cadastro internacional das profissões dos migrantes e refugiados, bem como análise das principais demandas entre as possíveis nações anfitriãs. Propõe-se, para este fim, a formação de um banco de dados relacional $^{26}$. Em casos de grandes crises humanitárias em região específica (como ocorre na Venezuela), um cadastro de demanda laboral e cooperação interna e internacional são mecanismos eficazes para a mitigação dos danos e ao beneficiamento das economias anfitriãs.

Entretanto, deve ser considerada a opinião do estrangeiro e a real capacidade de integração à nação acolhedora, à luz da proporcionalidade em sentido estrito. Uma decisão amparada unicamente na oferta e demanda de vagas de emprego, sem analisar fatores socioculturais e afetivos, bem como a liberdade do indivíduo, desrespeita a liberdade laborativa consagrada na Constituição Brasileira e diversos documentos internacionais, a exemplo do Pacto Internacional sobre os Direitos Econômicos, Sociais e Culturais e na Constituição, em seu art. $5^{\circ}$, XIII.

$\mathrm{O}$ uso cotidiano da técnica mitiga o agravamento dos problemas inerentes à desorganização das principais metrópoles brasileiras (MEIRELLES, 2000, p. 141) ${ }^{27}$. Ademais, o assentamento em massa é solução constitucionalmente pertinente para crises economicamente insuperáveis de refugiados. Para a sua viabilidade in concreto, é essencial a criação de um fundo comunitário para despesas com a seguridade social (VICENTINI, 2013). Afinal, o MERCOSUL é, além de área de livre comércio e união aduaneira, também um mercado comum. Os dos seus pressupostos é a livre circulação dos fatores de produção (as quatro liberdades). Dentre eles está a mão-de-obra. Logo, essencial a harmonização das políticas previdenciária (SAINZ, 1971), trabalhista e de capitais.

O controle jurisdicional também alcança a aplicação dos pressupostos de organização espacial da recepção de refugiados, com o fim de assegurar que não haja a expulsão pura e

\footnotetext{
${ }^{26}$ A Argentina, por exemplo, possui maior demanda por técnicos e trabalhadores de ofício. O Brasil possui necessidade de assistentes de escritórios e mecânicos, o Canadá de professores, a Colômbia de operadores de produção e a Guatemala de representantes de vendas. O Peru precisa de recepcionistas e os Estados Unidos de motoristas.

27 "Enquanto em 1970 a Região Metropolitana de São Paulo concentrava 43,4\% do valor da transformação industrial do País e 74\% do total de São Paulo, em 1985 tais índices caíram para 29,4\% e 56,6\%, respectivamente. [...] permaneceram concentrados os centros de decisão na região Sudeste e em São Paulo, havendo, na realidade, apenas a desconcentração das bases de operação dos grandes capitais."
} 
simples. É relevante o papel das sentenças estruturantes ${ }^{28}$ em caso de omissão do Executivo e Legislativo, nestes casos. Surgida nos Estados Unidos da América em 1954, com o caso Brown vs. Board of Education of Topeka (United States America Supreme Cort, 1954), questionavase a inconstitucionalidade da segregação racial em escolas americanas. Mostrou-se necessária uma structural injunction ${ }^{29}$ - implementação de uma reforma estrutural em um ente, organização ou instituição, com o objetivo de concretizar um direito fundamental, resolver litígios complexos, e até mesmo realizar política pública.

Seu rito pode seguir os exemplos das sentenças estruturantes que já integram o ordenamento jurídico brasileiro. É o caso da decisão que decreta a falência, o caso Raposa Serra do Sol, a decisão do Conselho Administrativo de Defesa Econômica de intervenção na sociedade empresária, quando necessária.

Sua principal característica é a remodelação da separação dos poderes, além de atenuar a regra da congruência. Seus mais relevantes amparos legais são a atipicidade das medidas executivas, acesso à ordem jurídica justa e efetividade da prestação jurisdicional. No caso em análise, a expulsão de refugiado de maneira desproporcional ou com vício de fundamentação requer não somente simples declaração de antijuridicidade pelo Judiciário, mas aplicabilidade concreta do assentamento segundo a profissionalização dos indivíduos, através de cooperação internacional. Logo, essencial o uso da técnica de sentença estruturante, para garantia do non refoulement, tanto na sua interpretação clássica, quanto ampliativa, pelo controle de juridicidade dos atos administrativos.

\section{CONCLUSÕES}

\footnotetext{
28 "É necessário que o julgador livre-se das amarras do pedido formulado, flexibilize os princípios da demanda e da congruência, para que, através de outra solução possa encontrar o resultado equivalente àquele aventado pelo autor na petição inicial, mas que não pode por ele ser previsto ao fazer o pedido [...] Verifica-se importante ressaltar que os julgados dos Tribunais superiores brasileiros movimentam-se na mesma direção, ou seja, a jurisprudência acompanha o entendimento e a aplicação das structural injunctions."

29 "Because these are class actions, because of the wide applicability of this decision, and because of the great variety of local conditions, the formulation of decrees in these cases presents problems of considerable complexity. [...] We have now announced that such segregation is a denial of the equal protection of the laws. In order that we may have the full assistance of the parties in formulating decrees, the cases will be restored to the docket, and the parties are requested to present further argument on Questions 4 and 5 previously propounded by the Court for the reargument this Term”. (United States America Supreme Cort, 1954)

Por serem ações de classe, devido à ampla aplicabilidade dessa decisão, e devido à grande variedade das condições locais, a formulação de decretos nesses casos apresenta problemas de considerável complexidade. [...]. Anunciamos que a segregação é uma negação da proteção das leis. Para que possamos ter total assistência das partes na formulação de decretos, os casos serão devolvidos ao processo, e as partes são intimadas a apresentar mais argumentos sobre as questões 4 e 5 anteriormente proposto pelo Tribunal para o reargumento deste Termo. (Tradução livre nossa)
} 
Constata-se a insuficiência fática do acesso às Cortes Internacionais para a proteção célere dos refugiados, tornando-se essencial o aperfeiçoamento da técnica jurídica dos sistemas judiciários internos, com o fim de controlar a juridicidade dos atos administrativos. Neste exame, o Judiciário deve utilizar como fundamento o non-refoulement como jus cogens e o controle de convencionalidade deste mandamento.

Há vedação absoluta de expulsão de refugiados para locais de perigo. Além disso, devese observar a proibição de não recepção e expulsão (mesmo para local seguro) injustificadas. O ato administrativo não é político e discricionário, mas sujeito ao exame da fundamentação, à luz da proporcionalidade em sentido amplo, em especial sob o prisma da necessidade.

Acerca deste aspecto, é possível a alegação de reserva do possível em relação à manutenção de refugiados no país. O referido argumento, contudo, necessita ser taxativamente demonstrado pelo Poder Público, que possui o ônus da prova: deve comprovar a insuficiência econômica absoluta na manutenção dos refugiados em solo nacional.

Neste sentido, os mais apurados estudos econômicos ressaltam os benefícios dos fluxos migratórios. Por outro lado, reconhecem as dificuldades em obtenção de retorno socioeconômico em caso de graves crises, com população de refugiados relevante em comparação à dos residentes no território específico do acolhimento.

Ainda assim, mesmo que que haja situação de crise de refugiados grave e generalizada que impeça a sua recepção, a consequência não será a expulsão pura e simples, mas a adoção de técnicas de assentamento ordenado, mediante a cooperação internacional. Trata-se de dever do administrador público, também sujeito ao controle jurisdicional.

\section{REFERÊNCIAS}

ABRÚCIO, Fernando Luiz; COSTA, Valeriano Mendes Ferreira. Reforma do Estado e o Contexto Federativo Brasileiro. São Paulo: Centro de Estudos da Fundação Konrad Adenauer, 1998.

ALMEIDA, Ana Flávia Ananias; SILVA, Laura Ferreira; LARA, Caio Augusto Souza. Las ochentas: o preço do refúgio. Percurso, [S.1.], v. 3, n. 30, p. 105 - 108, dez. 2019. ISSN 23167521. 
ARAÚJO, Adriano Alves de Aquino. Reve de Brezil: A inserção de um grupo de imigrantes haitianos em Santo André, São Paulo - Brasil. Santo André: Dissertação de Mestrado. Programa de Pós-Graduação em Ciências Humanas e Sociais, UFABC. 2015.

ARENDT, Hannah. A Condição Humana. 10 Edição. Rio de Janeiro: Forense Universitária, 2009.

ATKINSON, Anthony; STIGLITZ, Joseph. Lectures on public economics. New York: McGraw-Hill Book, 1980.

BONAVIDES, Paulo. Ciência Política. 19ª Edição. São Paulo: Malheiros, 2012.

BORJAS, George J; Grogger, Jeffrey; Hanson, Gordon H. Comment: On Estimating Elasticities Of Substitution. Em: Journal of the European Economic Association, vol. 10, $\mathrm{n}^{\mathrm{o}} 1$ (fevereiro de 2012), pp. 198-210. DOI: 10.2307/41426728.

BRASIL, Lei n. 13.445, de 24 de maio de 2017: Institui a Lei de Migração, Capítulo I DISPOSIÇÕES PRELIMINARES, Art. $1^{\circ}, \S 1^{\circ}$. Disponível em: http://www.planalto.gov.br/ccivil_03/_ato2015-2018/2017/lei/113445.htm. Último acesso em: 07 abr 2020.

BRASIL, Lei $\mathbf{n}^{0}$ 9.474, de 22 de julho 1997: Define mecanismos para a implementação do Estatuto dos Refugiados de 1951, e determina outras providências, TÍTULO I - DOS ASPECTOS CARACTERIZADORES, Capítulo I - DO CONCEITO, DA EXTENSÃO E DA EXCLUSÃO, Art. 1 ${ }^{\circ}$, III. Disponível em: http://www.planalto.gov.br/ccivil_03/leis/19474.htm. Último acesso em: 09 abr 2020.

CAPPELLETTI, Mauro; GARTH, Bryant. Acesso à justiça. Porto Alegre, RS: Sergio Antonio Fabris, 1988.

CONARE. Refúgio em Números. $1^{a}$ Edição. Ministério da Justiça e Segurança Pública, 2016. Disponível em: https://www.justica.gov.br/seus-direitos/refugio/refugio-em-numeros. Último acesso em: 18 de março de 2020.

CONARE. Refúgio em Números. $2^{a}$ Edição. Ministério da Justiça e Segurança Pública, 2017. Disponível em: https://www.justica.gov.br/seus-direitos/refugio/refugio-em-numeros. Último acesso em: 18 de março de 2020.

CONARE. Refúgio em Números. $3^{\text {a }}$ Edição. Ministério da Justiça e Segurança Pública, 2018. Disponível em: https://www.justica.gov.br/seus-direitos/refugio/refugio-em-numeros. Último acesso em: 18 de março de 2020.

CONARE. Refúgio em Números. $4^{a}$ Edição. Ministério da Justiça e Segurança Pública, 2019. Disponível em: https://www.justica.gov.br/seus-direitos/refugio/refugio-em-numeros. Último acesso em: 18 de março de 2020. 
COSTA, Bruno Ferreira; TELES, GÉSSICA. A Política de Acolhimento de Refugiados: Considerações sobre o Caso Português. In: Revista Interdisciplinar de Mobilidade Urbana, vol. 25 , n. 51, p. 29-46.

COUTO, Berenice Rojas. O Direito Social e a Assistência Social na Sociedade Brasileira: uma equação possível? 4ª edição. São Paulo: Cortez, 2010.

DELGADO, Gabriela Neves. A CLT aos 70 anos: Rumo a um Direito do Trabalho Constitucionalizado. Em: Revista do Tribunal Superior do Trabalho. Volume 79, n. 2, abr. a jun. 2013. P. 268-294.

FAGNANI, Eduardo. Ajuste econômico e financiamento da política social brasileira: Notas sobre o período 1993/98”. Campinas: Revista Economia e Sociedade, nº 13, dezembro de 1999.

FILHO, José Cláudio Monteiro de Brito. Trabalho Decente: Análise Jurídica da Exploração do Trabalho - Trabalho Forçado e outras Formas de Trabalho Indigno. P. 43-44. Editora LTR. São Paulo. 2004.

FLICKINGER, Hans-Georg. O direito de cidadania. Uma faca de dois gumes. $3^{\circ}$ Volume. Porto Alegre: Véritas, PUC-RS, 1998.

FLORES, Joaquín Herrera. A (Re)invenção dos Direitos Humanos. Florianópolis: Fundação Boiteux. 2009.

FLORES, Joaquín Herrera. Teoria Crítica dos Direitos Humanos. Rio de Janeiro: Lúmen Juris. 2009.

FREITAS, Luiz Fernando Calil. Direitos Fundamentais: Limites e Restrições. Porto Alegre: Livraria do Advogado. 2007.

GALBRAITH, John Kenneth. A Sociedade Justa: Uma Perspectiva Humana: tradução de Ivo Korytowski. Rio de Janeiro: Campus, 1996. p. 120-122.

HEGEL, Georg W. F. Princípios da filosofia do Direito. São Leopoldo: Unisinos, 2010.

HESSE, Konrad. A força normativa da Constituição. Porto Alegre: Sergio Antonio Fabris Editor, 1991. P. 15.

IAMAMOTO, M. V. Apresentação. In: MENEZES, M. T. Em busca da teoria: Políticas de assistência pública. São Paulo: Cortez, 1993. P. 11, apud COUTO, Berenice Rojas. O Direito Social e a Assistência Social na Sociedade Brasileira: uma equação possível? $4^{a}$ edição. São Paulo: Cortez, 2010. P. 165.

JORNAL NACIONAL Milhares de venezuelanos deixam o país para recomeçar no Brasil: Extremo Norte do Brasil virou novo horizonte para venezuelanos. Fugindo da crise, eles procuram trabalho. Jornal Nacional, 2017. Disponível em: http://g1.globo.com/jornal- 
nacional/noticia/2017/05/milhares-de-venezuelanos-deixam-o-pais-para-recomecar-nobrasil.html. Último acesso em: 13 de dezembro de 2017.

JUBILUT, Liliana Lyra. O Direito Internacional dos Refugiados e sua Aplicação no Ordenamento Jurídico Brasileiro. São Paulo: Editora Método, 2007.

KANT, Imannuel. Crítica da Razão Pura. Lisboa: Fundação Calouste GulbeKian, 1985, p. 87

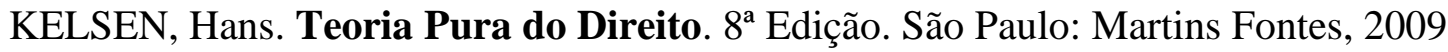

KREMER, Michael. Population Growth and Technological Change: One Million B.C. to 1990". Em: The Quarterly Journal of Economics, Edição 108, parte 3, p. 681-716. 1993.

LEITE, Larissa. O Devido Processo Legal Para o Refúgio no Brasil. Doutorado. Universidade de São Paulo - Direito. 2012.

LOPES, Cristiane. M. Sbalqueiro. O direito a não discriminação dos estrangeiros. Em: Boletim Científico da Escola Superior do Ministério Público da União, volume 37, p. 37-61. 2012.

MATOS, Yuri Matheus Araujo; BRITTO, Christiane Rabelo. Sonho, Conquista e Glória: a Migração Italiana ao Brasil no Período do Risorgimento. IV Simpósio Regional Direito e Cinema em Debate: Direito e Cinema Constitucional e Arte. Jacarezinho, PR: UENP. 1 ed. P. 531.

MAZZUOLI, Valério de Oliveira. Teoria Geral do Controle de Convencionalidade no Direito Brasileiro. São Paulo: Revista dos Tribunais, vol. 98, n. 889, p. 105-147, nov. 2009

MEIRELLES, José Ricardo. Impostos Indiretos no Mercosul e Integração. São Paulo: LTr, 2000. P. 141.

OSÓRIO, Luiz Felipe Brandão. Direitos Humanos, Direitos Internacionais e Relações Internacionais: uma reflexão crítica da teoria e aplicação no contexto contemporâneo. Relações Internacionais no Mundo Atual, [S.1.], v. 2, n. 16, p. 56-71, dez. 2013. ISSN 2316-2880. Disponível em: <http://revista.unicuritiba.edu.br/index.php/RIMA/article/view/732/558>. Acesso em: 24 abr. 2020. doi:http://dx.doi.org/10.21902/Revrima.v2i18.732.

PAULA, Bruna Vieira de. O Princípio do Non-Refoulement, sua Natureza Jus Cogens e a Proteção Internacional dos Refugiados. In: Revista do Instituto Brasileiro de Direitos Humanos, n. 7, dez 2006. P. 51-68.

PINHO, Humberto Dalla Bernadina; CÔRTES, Victor Augusto Passos Villani. As Medidas Estruturantes e a Efetividade das Decisões Judiciais no Ordenamento Jurídico Brasileiro. Em: Revista Eletrônica de Direito Processual. Vol. 13. P. 229-258. Rio de Janeiro. 2014. 
Disponível em: https://www.e-publicacoes.uerj.br/index.php/redp/article/view/11920/9333. Último acesso em 09 abr. 2020.

PIOVESAN, Flávia. Direitos humanos e o direito constitucional internacional. $7^{\text {a }}$ edição. São Paulo: Saraiva. 2006. P. 116- 118.

PIOVESAN, Flávia. Tratados Internacionais de Proteção dos Direitos Humanos: Jurisprudência do STF. Em: NETO, Cláudio Pereira de Souza; SARMENTO, Daniel; BINENBOJM, Gustavo (Coordenadores). Vinte anos da Constituição Federal de 1988. Rio de Janeiro: Lumen Juris. 2009.

RAMOS, André de Carvalho. Teoria Geral dos Direitos Humanos na ordem internacional. $3^{\circ}$ edição. São Paulo: Saraiva. 2013.

ROGUED, Patricia. Direitos e Deveres dos Refugiados na Lei $\mathbf{n}^{\mathbf{0}}$ 9.474/1997. Mestrado. Direito Político e Econômico. Universidade Presbiteriana Mackenzie. 2009.

SAINZ, Ricardo Calle. La Armonización Fiscal europea y el Impuesto sobre el Valor Añadido. In: INSTITUTO de Estudios Fiscales. EI Impuesto sobre el Valor Añadido: Primer Impuesto Europeo. Madrid: Fabrica Nacional de Moneda y Timbre. Ministério de Hacienda. 1971.

SANTOS, Boaventura de Sousa. Por uma Concepção Multicultural De Direitos Humanos. Coimbra: Revista Crítica de Ciências Sociais, n. 48, jun./1997.

SANTOS, Bruno Aguiar. Neoconstitucionalismo e ativismo: a ideologia fadada ao fracasso do arbítrio. Dissertação de Mestrado. Universidade Presbiteriana Mackenzie. São Paulo. 2017

SARLET, Ingo Wolfgang. A eficácia dos direitos fundamentais. Porto Alegre: Livraria dos Advogados, 2001.

SARLET, Ingo Wolfgang. Dignidade da pessoa humana e direitos fundamentais na Constituição Federal da 1988, $2^{a}$ edição. Porto Alegre: Livraria do Advogado. 2002. P.62.

SARLET, Ingo Wolfgang; FIGUEIREDO, Mariana Filchtiner. Reserva do possível, mínimo existencial e o direito à saúde: algumas aproximações. Revista de doutrina da $4^{\mathrm{a}}$ Região (TRF4), n. 24. Porto Alegre, jul. 2008. Disponível em: https://revistadoutrina.trf4.jus.br/artigos/edicao024/ingo_mariana.html. Último acesso em 09 abr. 2020.

SEN, Amartya. A ideia de Justiça. São Paulo: Companhia das Letras. 2018.

SHAW, Malcolm N. Direito Internacional. São Paulo: Martins Fontes, 2010

SILVA, Carla Ribeiro Volpini; ROMANO, Taisse June Barcelos Maciel. A proteção internacional dos refugiados ambientais fundamentada nos mecanismos de proteção do 
direito internacional dos refugiados. Revista Jurídica, [S.1.], v. 3, n. 48, p. 428 - 457, set. 2017. ISSN 2316-753X. Disponível em: <http://revista.unicuritiba.edu.br/index.php/RevJur/article/view/2188/1368>. Acesso em: 24 abr. 2020. doi:http://dx.doi.org/10.21902/revistajur.2316-753X.v3i48.2188.

SOUZA, Maria Cláudia da Silva Antunes de; GHILARDI, Hilariane Teixeira. Recursos hídricos, agropecuária e sustentabilidade: desafios para uma visão ecológica do planeta. Revista Jurídica, [S.1.], v. 2, n. 47, p. 78-98, jul. 2017. ISSN 2316-753X. Disponível em: <http://revista.unicuritiba.edu.br/index.php/RevJur/article/view/2027/1306>. Acesso em: 23 abr. 2020. doi:http://dx.doi.org/10.21902/revistajur.2316-753X.v2i47.2027.

SPOSATO, Karyna Batista; MACHADO, Luciana de Aboim. Justiça Juvenil Restaurativa e Novas Formas de Solução de Conflitos. São Paulo: Editora CLA Cultural. 2018.

SUPREMO TRIBUNAL FEDERAL. Tribunal Pleno. Arguição de Descumprimento de Preceito Fundamental n. 45 - Relator Min. Celso de Mello - Publicação: 29 de abril de 2004.

SUPREMO TRIBUNAL FEDERAL. Tribunal Pleno. Recurso Extraordinário n. 466.3431/SP - Relator Min. Cezar Peluso - Publicação: 03 de dezembro de 2008.

TAVARES, André Ramos. Teoria Geral dos Direitos Humanos na Ordem Internacional. Rio De Janeiro: Renovar, 2005.

TÉLÉMAQUE, Jenny. Imigração haitiana na mídia brasileira: entre fatos e representações. Centro de Filosofia e Ciências Humanas - Monografia para conclusão de Curso de Graduação, Escola de Comunicação da UFRJ. Rio de Janeiro, julho de 2012. Disponível em: <http://oestrangeiro.org/2012/08/02/haitianos-na-midia-brasileira-entre-fatose-representacoes/>. Acesso em 14/07/2017.

TRF-4, $3^{\text {a }}$ Turma. AGRAVO DE INSTRUMENTO n. 37636 PR 2007.04.00.037636-5. Relator: Marcelo de Nardi. Julgamento em 19 fev 2008.

UNITED STATES AMERICA SUPREME CORT. Brown v. Board of Education. Julgamento em 17 mai 1954.

VICENTINI, Marcelo Fonseca. Integração econômica - A Experiência Europeia e os Desafios do Mercosul. Revista de la Secretaría del Tribunal Permanente de Revisión. Año 1, $\mathrm{n}^{\circ} \quad 2$ 2 $2013.2 \quad$ P. 171-194. Disponível em: http://www10.iadb.org/intal/intalcdi/PE/2013/12752.pdf, último acesso em 13 de novembro de 2018. 